\title{
Stepped spillways with aerators: hydrodynamic pressures and air entrainment
}

\section{Vertedouros em degraus com aeradores: pressões hidrodinâmicas e entrada de ar}

\author{
Rute Ferla ${ }^{1}$ (D), Carolina Kuhn Novakoski ${ }^{1}$ (D), Priscila dos Santos Priebe ${ }^{1}$ (D), Mauricio Dai Prá ${ }^{1}$ (D), \\ Marcelo Giulian Marques ${ }^{1}$ (D) \& Eder Daniel Teixeira ${ }^{1}$ (D) \\ ${ }^{1}$ Universidade Federal do Rio Grande do Sul, Porto Alegre, RS, Brasil \\ E-mails: ruteferla@hotmail.com (RF), carolkn04@gmail.com (CKN), priscilaspriebe@gmail.com (PSP), mauricio.daipra@ufrgs.br (MDP), \\ mmarques@iph.ufrgs.br (MGM), eder.teixeira@ufrgs.br (EDT)
}

\begin{abstract}
The possibility of damage due to the phenomenon of cavitation leads the design of stepped spillways considering maximum specific discharges of 15 to $30 \mathrm{~m}^{2} / \mathrm{s}$, a limit considerably lower than that practiced on smooth chutes. Aerators promote the insertion of air in the flow, allowing for the increase of specific flow rates. This work analyzes the pressures on the vertical faces of the steps and the air entrainment coefficient in the flow, through an experimental study in a physical model with a stepped chute angle of $53.13^{\circ}$, considering the installation of aerators in different places of the channel. Comparing the tested conditions with the natural aeration, it is concluded that the installation of the aerator does not change the magnitude of the minimum extreme hydrodynamic pressures, but anticipates the beginning of the flow aeration. A new equation is proposed to estimate the air entrainment coefficient, as well as a methodology for forecasting extreme pressures on the vertical faces of the steps, both valid in the range $3.0 \leq \mathrm{Fr} \leq 6.0$.
\end{abstract}

Keywords: Hydraulic structures; Cavitation; Deflector.

\section{RESUMO}

Devido à possibilidade de danos em decorrência do fenômeno da cavitação, o projeto de vertedouros em degraus considera vazões específicas máximas de $15 \mathrm{a} 30 \mathrm{~m}^{2} / \mathrm{s}$, limite consideravelmente inferior ao praticado em calhas lisas. Aeradores promovem a inserção de ar no escoamento e podem viabilizar o incremento das vazões específicas. Este trabalho analisa as pressões sobre as faces verticais dos degraus e o coeficiente de entrada de ar no escoamento, através de estudo experimental em modelo físico de calha em degraus com ângulo de $53,13^{\circ}$, considerando a instalação de aerador em diferentes posições na calha. Comparando-se os resultados com a aeração natural, conclui-se que a instalação do aerador não altera a magnitude das pressões extremas mínimas na estrutura, mas antecipa o início da aeração no escoamento. Propõe-se nova equação para estimativa do coeficiente de entrada de ar no escoamento, bem como metodologia para previsão de pressões extremas nas faces verticais dos degraus, válidas no intervalo $3,0 \leq \mathrm{Fr} \leq 6,0$.

Palavras-chave: Estruturas hidráulicas; Cavitação; Defletor. 


\section{INTRODUCTION}

The design of spillways with stepped channels became common in dams built with the roller-compacted concrete (RCC) technique (Chanson, 1993), which were raised in the $19^{\text {th }}$ and early $20^{\text {th }}$ centuries (Matos \& Meireles, 2014). The expanding interest in the stepped spillways construction is due not only to the advantages of the RCC method - which, by using less cement content in the concrete, reduces the costs of the structure - but also to the greater dissipation of energy along the chute.

Hydraulic structures subjected to flows with speeds in the order of $30 \mathrm{~m} / \mathrm{s}$ or more - as is the case of dam spillways, for example - are susceptible to damage due to the phenomenon of cavitation (Falvey, 1990; Kells \& Smith, 1991). It is known, however, that small amounts of air in the water flow - that is, about $7 \%$ of air concerning the volume of water - can reduce or even eliminate the erosion damage resulting from cavitation. This is a conclusion indicated by Peterka (1953) and used as a criterion until today.

In the case of stepped chutes, the macrorugosity provided by the steps to the flow induces the turbulent boundary layer to reach the surface further upstream, when compared to smooth spillway chutes, allowing the natural aeration process to occur in advance. Downstream to the inception point of free-surface aeration, the structure will be protected from the damaging effects of cavitation, as long as there is sufficient air next to the concrete surface. On the other hand, upstream from the inception point, depending on the discharge, there is a high risk of damages due to cavitation.

Even though, in practical cases, stepped spillways have already been subject to notable floods without showing damage on the chute (Matos \& Meireles, 2014; Chanson, 2015), the design practice usually restricts the specific design discharges to values in the order of 15 to $30 \mathrm{~m}^{2} / \mathrm{s}$, as recommended by Pfister et al. (2006a) and Amador et al. (2009). Such recommendations are based on the understanding that stepped chutes are more prone to cavitation, when compared to smooth chutes, due to (i) the irregularities created by the steps protruding into the flow (Terrier, 2016) and (ii) the negative pressures that occur, especially, on the vertical faces of the steps, according to contributions of SánchezJuny And Dolz (2005), Sánchez-Juny et al. (2007), Osmar et al. (2018), Ferla et al. (2019) and Marques et al. (2019).

In the last two decades, experimental investigations have been carried out on physical models of stepped chutes with aerator systems (situation also called induced aeration), being able to mention, for example, the important contributions of Pfister et al. (2006a, 2006b), Zamora et al. (2008) and Terrier (2016). The authors analyze, in particular, the air concentration profiles in the flow, with the objective of (i) understanding the behavior of the flow in these situations, (ii) verifying the feasibility of increasing the specific discharges for the design of stepped spillways and/or (iii) developing design criteria. According to the authors' results, the use of aerator systems on stepped chutes is a viable alternative to flow aeration and, consequently, reduces the possibility of cavitation damage. However, the authors do not analyze the hydrodynamic pressures on the faces of the steps in these situations. The impact of the flow jet on the stepped chute, downstream of the deflector, changes the pressure distribution in that region and, accordingly, the pressure on the steps must be systematically investigated (Terrier, 2016).

Models for predicting hydrodynamic pressures in stepped spillways without aerator systems were developed by authors such as Sánchez-Juny et al. (2008), Amador et al. (2009) and Canellas (2020). However, methodologies for predicting pressures considering stepped spillways with deflector aerators are still inexistent or are in the development phase.

Concerning the point of installation of the aerator system along the chute, most investigations consider placing the aerator in the vicinity of the spillway (e.g., Pfister et al., 2006a, 2006b; Zamora et al., 2008; Mojtaba et al., 2015; Novakoski et al., 2020). Other works also consider installing the aerator system further downstream of the chute, however, suggesting the existence of a smooth chute upstream (e.g., Terrier, 2016). It is known that air entrainment in aerator systems is strongly affected by the approach flow Froude number Fr (Pfister \& Hager, 2010b). Higher Froude numbers are reached downstream of the chute and, therefore, it is to be expected that the performance of the aerator system will be better the further downstream it is placed. Nevertheless, depending on the discharge, the structure may be susceptible to cavitation damage even in the vicinity of the spillway crest and, therefore, it is suitable to install the aerator system further upstream.

The estimation of the most desirable position for installing the aerator system in a spillway can be done by evaluating the cavitation index. When the cavitation index, for a certain chute location and discharge, is lower than the cavitation index considered critical for that condition, then the installation of an aerator system may represent an interesting alternative to avoid the damage resulting from cavitation. The critical cavitation index for stepped spillways was proposed by authors such as Pfister et al. (2006a), Frizell et al. (2013) and Pfister \& Boes (2014), and is always more conservative than one for smooth channels.

In this perspective, this work attempts to contribute to the understanding of the pressures distribution behavior over the vertical step faces of a chute with aerator devices, through an experimental study in a physical model. Statistical parameters of the pressures are evaluated considering the aerator system placed in two regions of the chute: one in the vicinity of the spillway crest and another further downstream, considering, in the last case, the existence of steps also upstream the aerator system. Based on the pressure measurement results, equations that allow the estimation of hydrodynamic pressures on the vertical faces of the steps are proposed. Also, considerations regarding the aerator system are presented, based on the analysis of the air entrainment coefficient.

\section{EXPERIMENTAL SETUP AND INSTRUMENTATION}

The experiments were carried out in a stepped spillway model of the Laboratory of Hydraulic Works (Laboratório de Obras Hidráulicas - LOH), located at the Institute of Hydraulic Research (Instituto de Pesquisas Hidráulicas - IPH) of the Federal University of Rio Grande do Sul (UFRGS), Brazil. The crest shape of the spillway follows the standard Waterways Experiment Station (WES) developed by the U.S. Army Corps of Engineers, and is freely operated (without gates). As shown in Figure 1, a stepped 
rectangular chute is located downstream of the WES crest, whose angle of pseudo-bottom against the horizontal $(\alpha)$ is constant and equal to $53.13^{\circ}(1 \mathrm{~V}: 0.75 \mathrm{H})$. Similar chute angles are used in the practice, such as in the spillways of Dona Francisca Dam (Brazil) and Pedrógão Dam (Portugal), for example, both built using the RCC technique, and are also usual in other similar experimental works (e.g., Sánchez-Juny et al., 2007, 2008; Meireles et al., 2012). The chute is $0.50 \mathrm{~m}$ wide with 52 steps $0.06 \mathrm{~m}$ high $\left(\mathrm{h}_{\mathrm{s}}\right)$ each, totaling $3.90 \mathrm{~m}$ in length. Considering a hypothetical prototype whose steps are $1.20 \mathrm{~m}$ high, the geometric scale of the model will be $1: 20$, whereas, if it is considered a prototype with steps that are $0.60 \mathrm{~m}$, the scale will be equal to 1:10.

To add air in the lower portion of the flow, a deflector (aerator device) and an air chamber and duct (air supply device) were used. The proposed aerator system is similar to that used by Terrier (2016). The air chamber has a wide section in order to reduce the air head losses in the aerator system and the subpressure $(\Delta \mathrm{p})$ in the cavity under the jet. The deflector has a height $(\mathrm{t})$ of $0.01 \mathrm{~m}$ and an angle $(\theta)$ equal to $7.6^{\circ}$ - similar angles were used by Pfister et al. (2006a) and Terrier (2016) - and extends the entire width of the channel. An air duct $0.70 \mathrm{~m}$ long (internal diameter $\varnothing 0.069 \mathrm{~m}$ ) is coupled to the air chamber, where indirect measurement of the air discharge is performed, by measuring the air velocity, with the aid of a Pitot-Prandtl probe (Dwyer 166-12) coupled to a differential pressure transducer (Rücken RTBP-420DIF), as shown in Figure 1. The aerator system described was placed and analyzed in two different locations of the chute: both immediately downstream of the WES crest, on step number 1 (S1, Figure 1a), as well as in the vicinity of step number 10 (S10, Figure 1b). Such conditions were tested independently, that is, when the aerator system was installed on step number 1, there was no aerator system operating on step number 10 and vice versa.
The determination of the aerator system location on the chute was based on the cavitation index (see Appendix A).

Pressure measurements on the vertical faces of the steps were performed using piezoresistive sensors (Omega PX419, Sitron SP96 and Hytronic TM25), for both situations shown in Figure 1. The pressure taps were positioned on the channel axis (therefore, $0.25 \mathrm{~m}$ away from each side wall), in the vicinity of the external edge of each step, according to the conclusions of Sánchez-Juny \& Dolz (2005), Sánchez-Juny et al. (2007) and Tassinari et al. (2020), for example.

The pressure behavior was evaluated based on the results of extreme pressures with non-exceedance probability of $5 \%$, $1 \%$ and $0.1 \%\left(\mathrm{P}_{5 \%}, \mathrm{P}_{1 \%}\right.$ and $\left.\mathrm{P}_{0.1 \%}\right)$ on the vertical faces of the steps. Similar statistical parameters of extreme pressures were used by Sánchez-Juny et al. $(2007,2008)$ and Osmar et al. (2018). It was chosen to analyze only minimum extreme pressures on the vertical face due to the conclusions of Sánchez-Juny et al. (2007). Flow pressures measured in tests with natural aeration were used to evaluate the performance of the proposed aeration system.

The specific discharges (q) tested range from 0.05 to $0.50 \mathrm{~m}^{2} / \mathrm{s}$ and were measured using electromagnetic devices (Incontrol CEV-1000, Siemens 79-MAG-6000 and Emerson 09-FM-D119). Considering a hypothetical prototype with 1:10 geometric model scale, these correspond to specific discharges in the range of 2 to $16 \mathrm{~m}^{2} / \mathrm{s}$ up to 5 to $45 \mathrm{~m}^{2} / \mathrm{s}$ (considering the scale of $1: 20$ ). All tested discharges correspond to the skimming flow regime on the chute. Flow depths were measured using a common point gauge. In the situation where the aerator system is installed on step number 10 , only cases where $\mathrm{q} \geq 0.20 \mathrm{~m}^{2} / \mathrm{s}$ were considered, since, in other conditions, the turbulent boundary layer reaches the flow surface upstream of step number 10. Table 1 presents a summary of the test conditions.

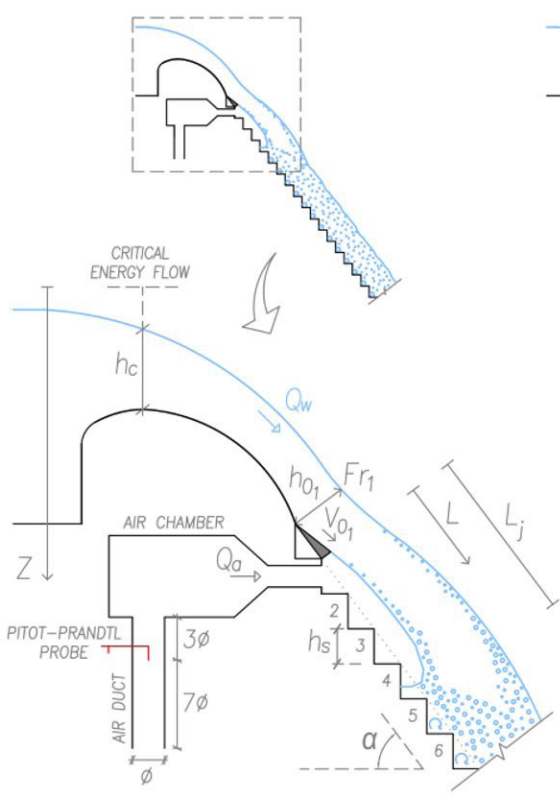

(a) $\mathrm{S} 1$

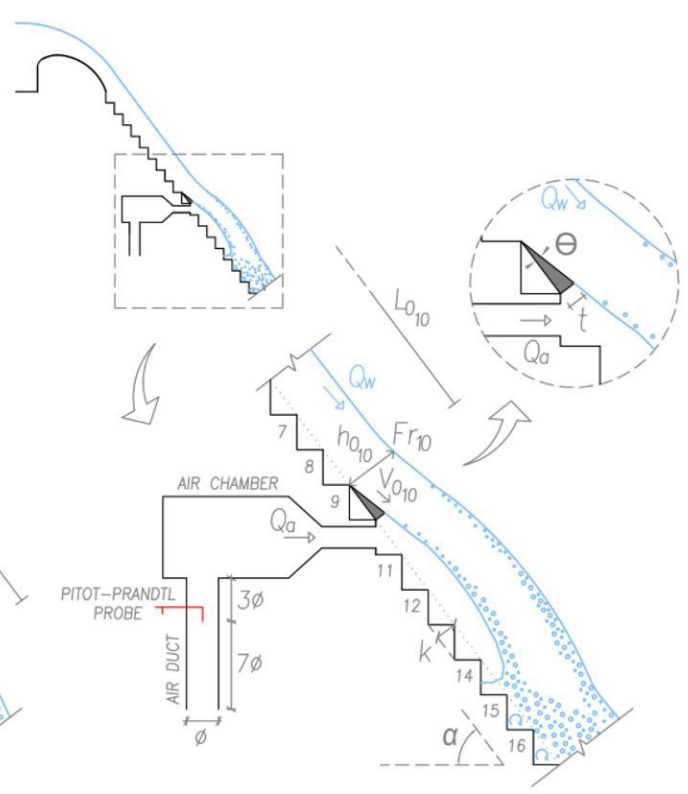

(b) S10

Figure 1. Schematic representation of the experimental conditions considering (a) aerator system placed on step number 1 (S1) and (b) on step number 10 (S10). The conditions S1 and S10 were tested independently. The subscript (1 or 10) denotes the step where the aerator system was placed (subscript 1 for S1 and subscript 10 for S10). For more details, see the list of notations at the end of the paper. 
Table 1. Summary of test conditions.

\begin{tabular}{cccccc}
\hline $\mathrm{q}\left(\mathbf{m}^{2} / \mathbf{s}\right)$ & $\mathbf{h}_{\mathbf{c}} \mathbf{( m )}$ & $\mathbf{h}_{\mathbf{0 1}} \mathbf{( m )}$ & $\mathbf{F r}_{\mathbf{1}}$ & $\mathbf{h}_{\mathbf{0 1 0}} \mathbf{( m )}$ & $\mathbf{F r}_{10}$ \\
\hline 0.054 & 0.067 & 0.020 & 6.10 & - & - \\
0.082 & 0.088 & 0.029 & 5.30 & - & - \\
0.108 & 0.106 & 0.039 & 4.48 & - & - \\
0.150 & 0.132 & 0.050 & 4.28 & - & - \\
0.200 & 0.160 & 0.064 & 3.94 & 0.053 & 5.23 \\
0.300 & 0.209 & 0.091 & 3.49 & 0.073 & 4.86 \\
0.400 & 0.254 & 0.117 & 3.19 & 0.091 & 4.65 \\
0.500 & 0.294 & 0.140 & 3.05 & 0.108 & 4.50 \\
\hline
\end{tabular}

\section{RESULTS AND DISCUSSIONS}

\section{Air entrainment coefficient}

The air intake in an aerator system is quantified based on the air entrainment coefficient ( $\beta$, Equation 1). The coefficient $\beta$ represents only the amount of air inserted by the aerator system in relation to the water discharge, without considering the relationship between air entrainment and downstream flow behavior. Furthermore, it does not consider the air entrainment through the surface. For these reasons, it may not be considered an important parameter for some researchers, as suggested by Pfister \& Hager (2010a). However, it is largely the most common parameter used to describe the efficiency of aerator systems placed on spillways.

$\beta=\frac{Q_{a}}{Q_{w}}$

where $Q_{a}$ is the air flow $\left[\mathrm{m}^{3} / \mathrm{s}\right]$ and $\mathrm{Q}_{\mathrm{w}}$ is the water flow $\left[\mathrm{m}^{3} / \mathrm{s}\right]$, see Figure 1.

The existing equations for estimating $\beta$ coefficient in stepped spillways are mostly a function of $\mathrm{Fr}$, as suggested by Pfister et al. (2006b) and Zamora et al. (2008), or Fr in association with geometric characteristics of the structure, such as the proposal by Terrier (2016). The last author also suggests that the air entrainment coefficient $\beta$ can be expressed as a linear function of the relationship between the jet length $\left(\mathrm{L}_{\mathrm{j}}\right)$ and the flow depth over the deflector $\left(\mathrm{h}_{0}\right)$.

Figure 2 shows the $\beta$ coefficient measured for all conditions indicated in Table 1 , together with $\beta$ coefficient estimated according to Equation 2 and Equation 3, both suggested by Terrier (2016).

$\beta=0.0077 \frac{L_{j}}{h_{0}}$

$\beta=0.013 \operatorname{Fr}(1+\operatorname{sen} \alpha)^{1,5}(1+\tan \theta)^{3}-0.096$

where $L_{j}$ is the jet length $[\mathrm{m}], \mathrm{h}_{0}$ is the water flow depth over the deflector $[\mathrm{m}], \mathrm{Fr}$ is the approach flow Froude number, $\alpha$ is the chute angle and $\theta$ is the deflector angle, see Figure 1.

Figure 2 suggests that the data obtained with the aerator system placed on step number 1 (S1) follow the trend indicated by Equation 2, however, the same does not happen for the data collected with the aerator system placed on step number 10 (S10).
Equation 3 overestimated, in all cases, the measured $\beta$ coefficient, as it can be seen in Figure 2.

Considering the data measured in the present study, the authors propose the relationship shown in Equation $4\left(\mathrm{R}^{2}=0.97\right.$; $3.0 \leq \mathrm{Fr} \leq 6.0)$ to estimate the $\beta$ coefficient, function of Fr and geometric characteristics of the aerator system, among other parameters. Equation 4 is the result of a combination of some of the main dimensionless parameters set out in the literature (see Terrier, 2016). In Equation 4, both parameters $h_{0}$ and $\mathrm{Z}$ (see Figure 1) are related to the location chosen for placing the aerator system along the chute. Equation 4 proved to be adequate to calculate the $\beta$ coefficient regardless of the location where the aerator system is installed (in this case, conditions S1 or S10), as suggested in Figure 3.

$\beta=0.196 e^{-1.106 \Psi}$ where $\Psi=\frac{h_{0} V_{0}^{2}}{Z \operatorname{tFr} 2 g}$

where $\mathrm{V}_{0}$ is the average flow velocity over the deflector $[\mathrm{m} / \mathrm{s}], \mathrm{g}$ is the gravitational acceleration $\left[\mathrm{m} / \mathrm{s}^{2}\right], \mathrm{Z}$ is the flow energy parameter $[\mathrm{m}]$ and $\mathrm{t}$ is the deflector height $[\mathrm{m}]$, see Figure 1.

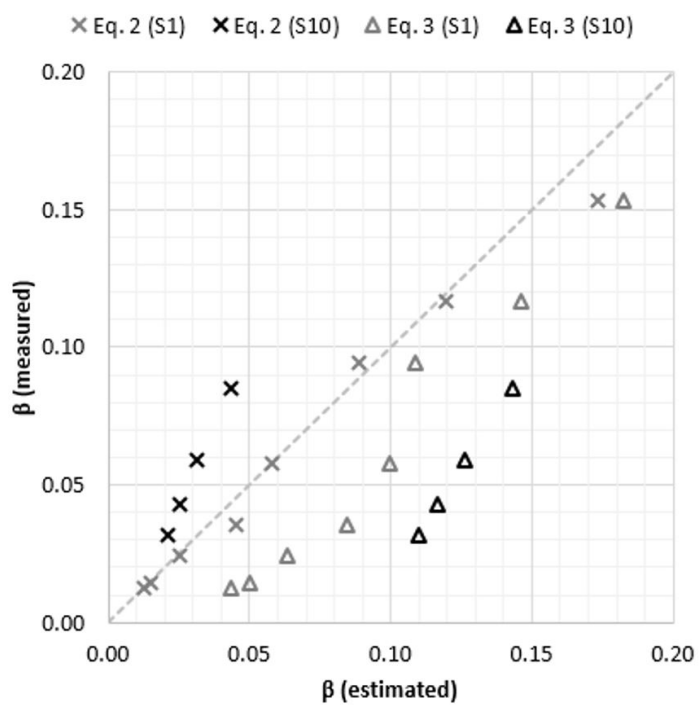

Figure 2. Air entrainment coefficient estimated according to Terrier (2016).

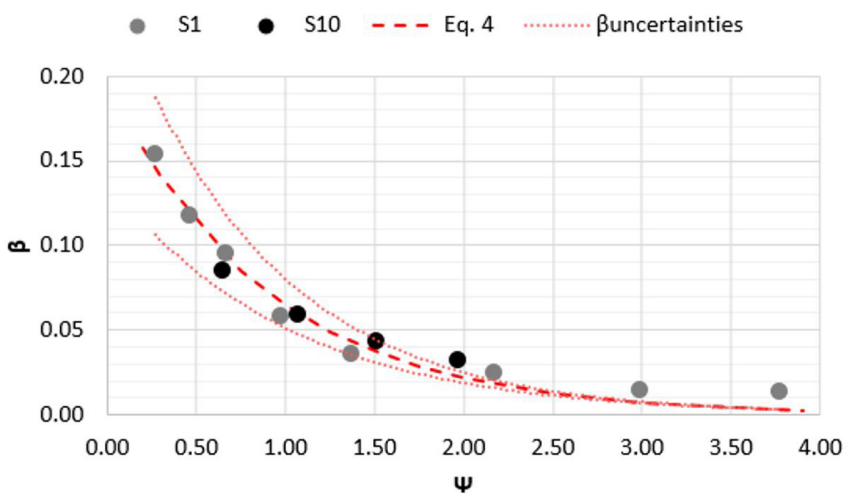

Figure 3. Air entrainment coefficient as a function of $\Psi$. 
Equation 4 does not consider the subpressure under the jet because this parameter was not significant (in this region, the pressure measurements registered values close to atmospheric pressure), which further suggests that the potential head losses in the air supply device do not influence the results.

The main uncertainties that may be associated with Equation 4 concern the measurements of parameter $h_{0}$ and the $\beta$ coefficient itself. For the first one, the uncertainty is related to the oscillation of free surface flow, perpendicular to the pseudo-bottom of the channel. In reduced physical models, such oscillation can be minimized with the insertion of elements that ensure a homogeneous flow distribution (so-called guiding walls). In the case of the structure used in the present research, the oscillations of free surface led to maximum variations in the order of $8 \%$ in $h_{0}$, which reflects differences in the order of $5 \%$ in parameter $\Psi$, not contributing to considerable variations in the results. The uncertainties related to the $\beta$ coefficient refer to the accuracy of the instrument used to measure air velocity. Figure 3 presents the envelopes curves that consider adjustments to the $\beta$ coefficient, taking into account the errors associated with the differential pressure transducer, represented as $\beta_{\text {uncertainties }}$ in the caption. As Figure 3 suggests, there are considerable uncertainties particularly in cases where the $\beta$ coefficient is higher than 0.10 . Thus, Equation 4 should be used with caution in these cases.

According to Equation 4, it is necessary to know the depth $\mathrm{h}_{0}$ in the deflector (here called $\mathrm{h}_{01}$ or $\mathrm{h}_{010}$, depending on the analyzed condition) to estimate the $\beta$ coefficient. In physical models, such depth can be easily measured, for example, using a common point gauge. However, in the impossibility of measuring depth $\mathrm{h}_{0}$ (i.e., in the design phase or existing structures, for example), the authors suggest estimating $\mathrm{h}_{0}$ as follows:

- Considering the aerator system placed in the vicinity of the spillway crest (a situation similar to the one here called S1), depth $h_{01}$ can be theoretically defined, based on the equality of flow energy between the critical section and the deflector section, disregarding energy losses;

- Considering the aerator system placed in further downstream positions along the chute (a situation similar to the one here called S10), the estimation of $h_{010}$ can be made based on Equation 5, proposed by Meireles et al. (2012), with $\mathrm{h}_{\mathrm{i}}$ being the flow depth at the inception point of natural aeration, $\mathrm{L}_{0}$ the distance from the spillway crest to the position of the deflector and $\mathrm{L}_{\mathrm{i}}$ the distance until the inception point of natural aeration. Equation 5 should be used only in the non-aerated flow segment, that is, it is valid in the interval of $0.1 \leq \mathrm{L}_{0} / \mathrm{L}_{\mathrm{i}} \leq 1$. In this case, it is recommended to use Equation 6 and Equation 7, respectively, to estimate $h_{i}$ and $\mathrm{L}_{\mathrm{i}}$, as also proposed by Meireles et al. (2012), where Fr* refers to the roughness Froude number (Equation 8).

$\frac{h_{010}}{h_{i}}=1.17-0.25 \frac{L_{0}}{L_{i}}+\frac{0.084}{L_{0} / L_{i}}$

$\frac{h_{i}}{k}=0.35 \mathrm{Fr}^{*} 0.59$

$\frac{L_{i}}{k}=6.75 \mathrm{Fr}^{*} 0.76$
$\operatorname{Fr}^{*}=\frac{q}{\sqrt{g \operatorname{sen} \alpha k^{3}}}$

where $h_{i}$ is the inception aeration flow depth $[\mathrm{m}], \mathrm{L}_{0}$ is the deflector position length along the chute $[\mathrm{m}], \mathrm{L}_{\mathrm{i}}$ is the inception aeration flow length $[\mathrm{m}], \mathrm{k}$ is the step roughness $[\mathrm{m}]$, and $\mathrm{Fr}^{*}$ is the roughness Froude number.

In the present study, the measured values of $h_{01}$ and $\mathrm{h}_{010}$ were compared with the flow depths calculated based on the suggested criteria, and the differences observed were always less than $15 \%$ (in case of $\mathrm{h}_{01}$ ) and $5 \%$ (in case of $\mathrm{h}_{010}$ ).

\section{Pressure distribution along the chute}

The hydrodynamic pressures measured in situations with the aerator system installed both on step number 1 (S1) and on step number 10 (S10) were compared to the same pressures obtained in natural aeration condition (NAT), for $\mathrm{q}=0.20 \mathrm{~m}^{2} / \mathrm{s}$ (Figure $4 \mathrm{a}$ ) and $\mathrm{q}=0.50 \mathrm{~m}^{2} / \mathrm{s}$ (Figure $4 \mathrm{~b}$ ). The pressure behavior was evaluated based on the results of extreme pressures $\left(\mathrm{P}_{5 \%}, \mathrm{P}_{1 \%}\right.$ and $\left.\mathrm{P}_{0.1 \%}\right)$ on the vertical faces of the steps, represented on the ordinate axis in Figure 4, where the abscissa axis refers to the step number along the chute. Figure 4 also indicates the location of the beginning of natural aeration in the flow, considering the NAT condition (identified as "Inception point NAT" in the caption).

Concerning the behavior of the pressure profiles along the chute, Figure 4 indicates that the induced aeration conditions (S1 and S10) present measured values close to zero immediately upstream of the jet impact on the channel, which was already expected since immediately after the flow comes into contact with the deflector (that is placed on step number 1 for $\mathrm{S} 1$ condition, and on step number 10 for S10, see Figure 1), it is launched over the steps and loses contact with the chute. In that region, therefore, it is reasonable that the pressure measured is close to zero (which indicates atmospheric pressure).

The $\mathrm{S} 1$ configuration is similar to the NAT condition, except on the region upstream of the jet impact on the channel. After the jet impact, there is a transition region between the pressure values measured in S1 and NAT conditions. Finally, it can be assumed that $\mathrm{S} 1$ and NAT conditions are similar downstream of step number 15 (approximately), as it can be observed in Figure 4.

The S10 configuration has two sections with different behaviors in the chute: one of them, upstream of step number 10 , which is subject to the natural aeration of the flow, and another, downstream of step number 10 , subject to the action of the aerator system. As observed in S1 condition, after the impact of the jet on the steps there is also a transition region in S10 condition until the pressure behavior reaches the values collected in the NAT condition.

Naturally, the absolute values of the statistical parameters increase with the increasing flow and decreasing statistical parameters. The minimum absolute values of $\mathrm{P}_{0.1 \%}$ can be about two or three times greater than those of $\mathrm{P}_{5 \%}$. Therefore, the designer must carefully select the parameter to be considered, in each situation.

In the primary investigation it can be inferred, by Figure 4, that both S1 and S10 conditions did not significantly modify the values of the statistical parameters, when compared with the NAT condition. In most of the cases shown in Figure 4, the hydrodynamic 

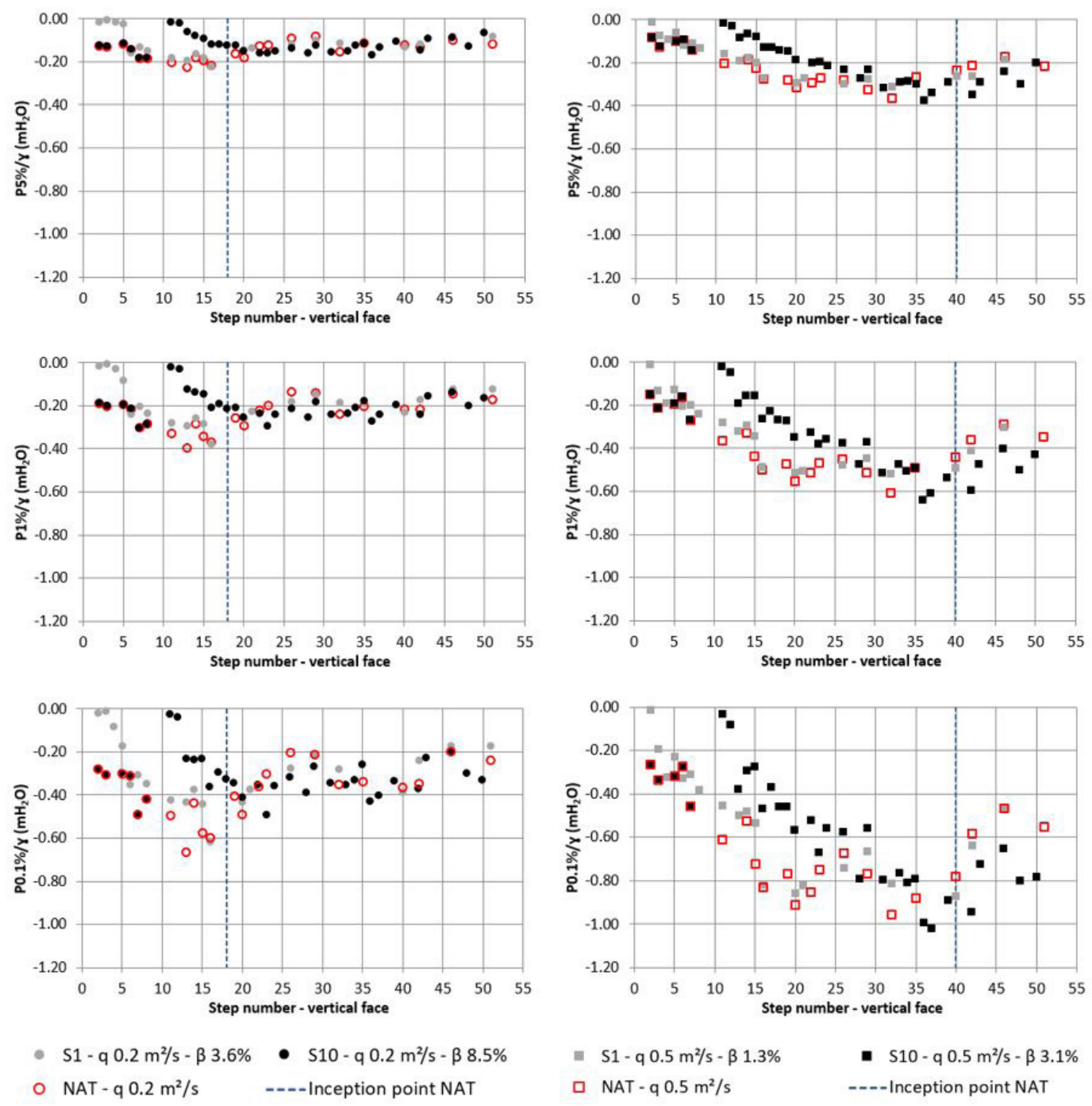

(a)

(b)

Figure 4. Statistical parameters of the hydrodynamic pressures $\left(\mathrm{P}_{5 \%}, \mathrm{P}_{1 \%}\right.$ and $\left.\mathrm{P}_{0.1 \%}\right)$ on the vertical faces of the steps, where (a) $q=0.20 \mathrm{~m}^{2} / \mathrm{s}$ and (b) $\mathrm{q}=0.50 \mathrm{~m}^{2} / \mathrm{s}$. Values indicated in $\mathrm{mH}_{2} \mathrm{O}$, as a ratio between pressure at the local under analysis $\mathrm{P}[\mathrm{Pa}$ and specific weight of water $\gamma\left[\mathrm{N} / \mathrm{m}^{3}\right]$.

pressures under NAT, S1 or S10 conditions were very similar (except for the regions influenced by the impact of the flow jet on the steps). Furthermore, regardless of the water flow, the extreme (minimum) values observed in the three conditions analyzed are similar. Therefore, it can be stated that induced aeration does not change the magnitude of the pressures on the steps and that it presents values similar to those observed in natural aeration. However, the induced aeration conditions present biphasic flow, composed of water and air, already close to the impact of the jet. That fact can reduce the chance of damage to the structure, due to the cavitation phenomenon (as long as the air concentration is enough).

According to Figure 4a, the inception point of natural aeration (Inception point NAT) occurs in the vicinity of step number 18 . Upstream of this step, considering the NAT configuration, the flow is monophasic, and, therefore, the spillway structure may be susceptible to damage as a result of the cavitation phenomenon. In Figure $4 \mathrm{~b}$ the situation is even more critical: the beginning of natural aeration in the flow occurs on step number 40 and, in this case, the chute is susceptible to damage in almost its entire length. The minimum values of $\mathrm{P}_{0.1 \%}$ in the NAT condition reach the order of -0.60 to $-1.00 \mathrm{~m}$, which would correspond, in a real structure, to circumstances prone to the development of the cavitation phenomenon. Although minimum values similar to those of the NAT condition have been reached in $\mathrm{S} 1$ and $\mathrm{S} 10$ conditions, in induced aeration the flow is now composed of a mixture of air and water close to the jet impact. Thus, the possibility of damage to the chute is lower.

In Figure 4a, it can be seen that the S1 condition presented a higher magnitude of minimum pressures than the $\mathrm{S} 10$ condition. The opposite was noticed in Figure 4b. The authors suggest that this may be related to the $\beta$ coefficient, which is considerably higher in the S10 condition of Figure $4 \mathrm{a}(\beta=8.5 \%$, as indicated in the caption) compared to the other conditions. However, this hypothesis can only be confirmed after an analysis of the air concentration profiles in the flow. 


\section{Pressure prediction methodology}

In this section, analytical expressions to estimate the pressures on the vertical faces of the steps are proposed, based on non-exceedance probabilities of $5 \%, 1 \%$ and $0.1 \%$. The S1 and S10 configurations were considered in the interval $0.20 \mathrm{~m}^{2} / \mathrm{s} \leq \mathrm{q} \leq 0.50 \mathrm{~m}^{2} / \mathrm{s}$. The analysis of the statistical parameters results indicated that the pressure behavior is well represented by Equation 9 (ordinate axis), together with the position ratio (abscissa axis) corresponding to (L-L)/ $\mathrm{h}$. The curve resulting from the application of the indicated relations follows a second-degree polynomial function, regardless of the probability considered, as suggested by Equation 10.

$\Omega=\frac{P}{\rho_{w} g} h_{s} \frac{h_{c}}{Z^{3}} F r^{2}$

$\Omega=a+b x+c x^{2}$, where $x=\frac{L-L_{j}}{h_{c}} ; 0 \leq x \leq 10$

where $h_{s}$ is the step height $[\mathrm{m}], \mathrm{h}_{\mathrm{c}}$ is the critical flow depth $[\mathrm{m}]$, $\varrho_{w}$ is the density of water $\left[\mathrm{kg} / \mathrm{m}^{3}\right], \mathrm{L}$ is the longitudinal length along the chute $[\mathrm{m}]$, see Figure 1 . The coefficients $\mathrm{a}, \mathrm{b}$ and $\mathrm{c}$ are indicated in Table 2.
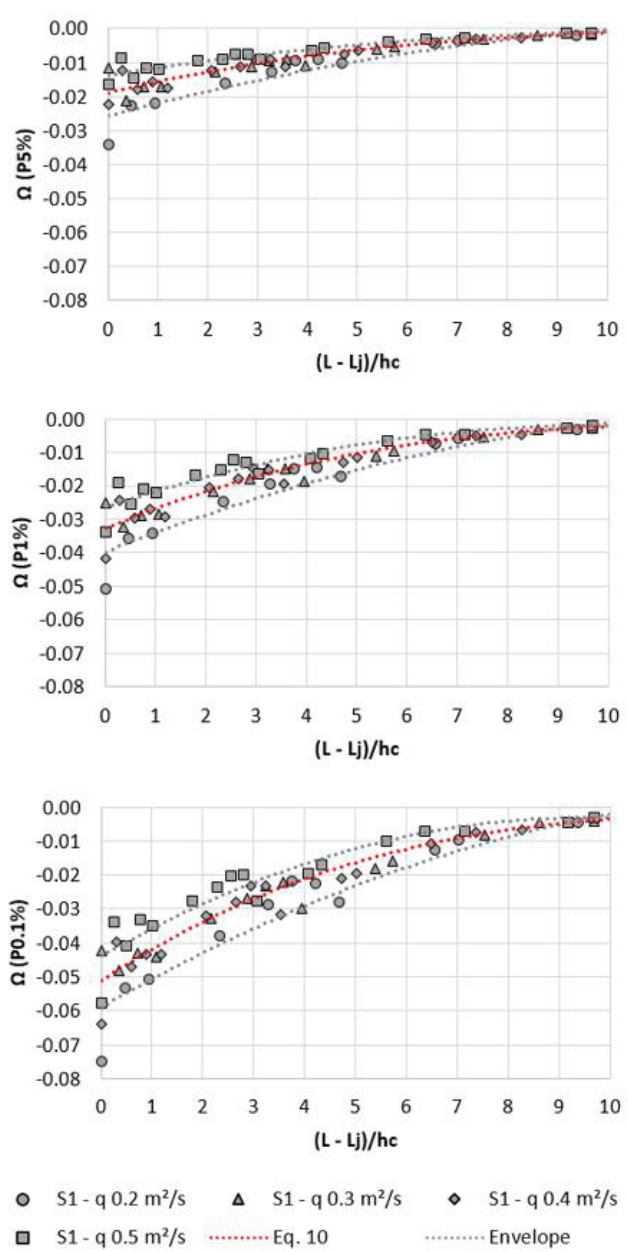

(a)
Table 2. Coefficients of Equation 10.

\begin{tabular}{cccccc}
\hline & & $\mathbf{a}$ & $\mathbf{b}$ & $\mathbf{c}$ & $\mathbf{R}^{2}$ \\
\hline S1 & $\mathrm{P}_{5 \%}$ & $-1.79 \times 10^{-2}$ & $2.62 \times 10^{-3}$ & $-9.25 \times 10^{-5}$ & 0.80 \\
& $\mathrm{P}_{1 \%}$ & $-3.07 \times 10^{-2}$ & $4.58 \times 10^{-3}$ & $-1.63 \times 10^{-4}$ & 0.86 \\
& $\mathrm{P}_{0.1 \%}$ & $-4.79 \times 10^{-2}$ & $7.11 \times 10^{-3}$ & $-2.53 \times 10^{-4}$ & 0.88 \\
\multirow{5}{*}{ S10 } & $\mathrm{P}_{5 \%}$ & $-9.35 \times 10^{-3}$ & $9.53 \times 10^{-4}$ & $-2.26 \times 10^{-5}$ & 0.90 \\
& $\mathrm{P}_{1 \%}$ & $-1.70 \times 10^{-2}$ & $1.96 \times 10^{-3}$ & $-5.80 \times 10^{-5}$ & 0.92 \\
& $\mathrm{P}_{0.1 \%}$ & $-2.86 \times 10^{-2}$ & $3.54 \times 10^{-3}$ & $-1.16 \times 10^{-4}$ & 0.91 \\
\hline
\end{tabular}

The resulting adjustment curves are shown in Figure $5 \mathrm{a}$ ( $\mathrm{S} 1$ configuration) and Figure 5b ( $\mathrm{S} 10$ configuration), while Table 2 presents the coefficients of Equation 10, according to each configuration and associated probability. The proposed adjustment, represented in Equation 10, resulted in a coefficient of determination $\left(\mathrm{R}^{2}\right)$ between 0.80 and 0.90 , approximately, which suggests an adequate correlation between the data and the expression, being valid in the range $0 \leq\left(\mathrm{L}-\mathrm{L}_{\mathrm{j}}\right) / \mathrm{h}_{\mathrm{c}} \leq 10$.

For all the statistical parameters analyzed, the results of the $\mathrm{S} 1$ condition were more dispersed to the adjustment indicated in Table 2 when compared to the $\mathrm{S} 10$ condition, as can be seen in Figure 5. While, for the $\mathrm{S} 10$ configuration, the maximum difference between the measured and predicted pressure values (according
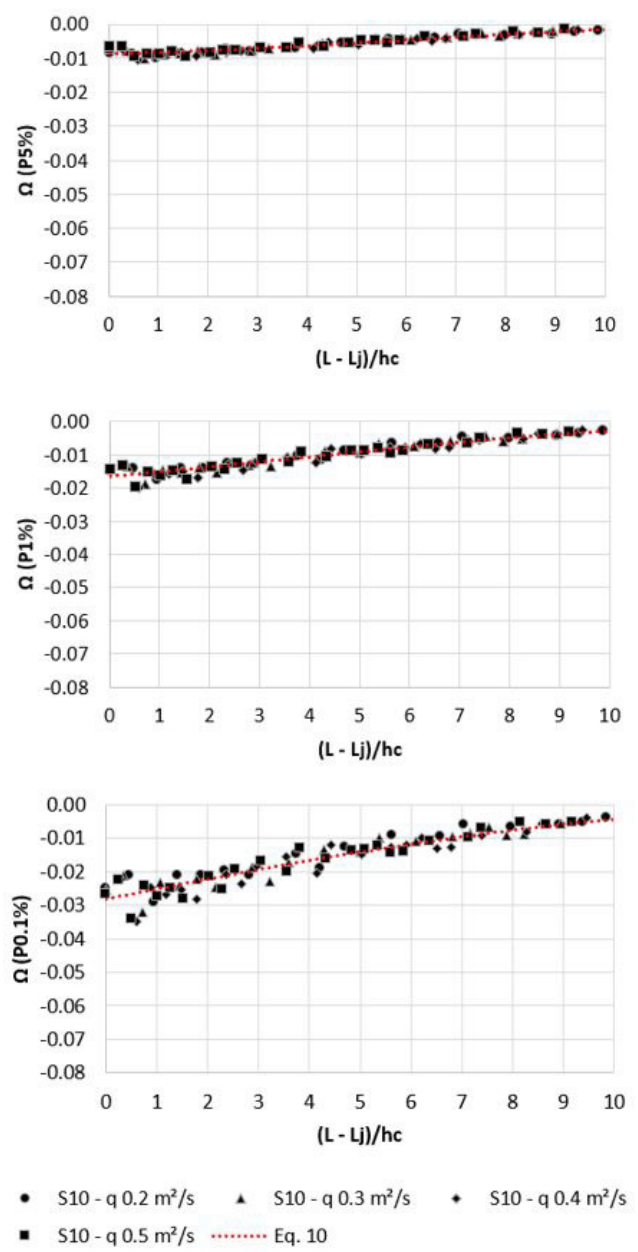

(b)

Figure 5. Behavior of the adjustment equation for predicting pressures in (a) S1 and (b) S10 configurations. 
Table 3. Coefficients of Equation 10 considering the envelope curves of S1 condition.

\begin{tabular}{|c|c|c|c|c|c|c|c|}
\hline & & \multicolumn{3}{|c|}{ Superior envelope } & \multicolumn{3}{|c|}{ Inferior envelope } \\
\hline & & $\mathbf{a}$ & b & c & $a$ & b & c \\
\hline \multirow{3}{*}{ S1 } & $\mathrm{P}_{5 \%}$ & $-1.37 \times 10^{-2}$ & $2.30 \times 10^{-3}$ & $-1.03 \times 10^{-4}$ & $-2.57 \times 10^{-2}$ & $3.84 \times 10^{-3}$ & $-1.33 \times 10^{-4}$ \\
\hline & $\mathrm{P}_{1 \%}$ & $-2.64 \times 10^{-2}$ & $5.00 \times 10^{-3}$ & $-2.56 \times 10^{-4}$ & $-3.96 \times 10^{-2}$ & $5.85 \times 10^{-3}$ & $-2.01 \times 10^{-4}$ \\
\hline & $\mathrm{P}_{0.1 \%}$ & $-4.39 \times 10^{-2}$ & $8.61 \times 10^{-3}$ & $-4.54 \times 10^{-4}$ & $-5.90 \times 10^{-2}$ & $8.64 \times 10^{-3}$ & $-2.95 \times 10^{-4}$ \\
\hline
\end{tabular}

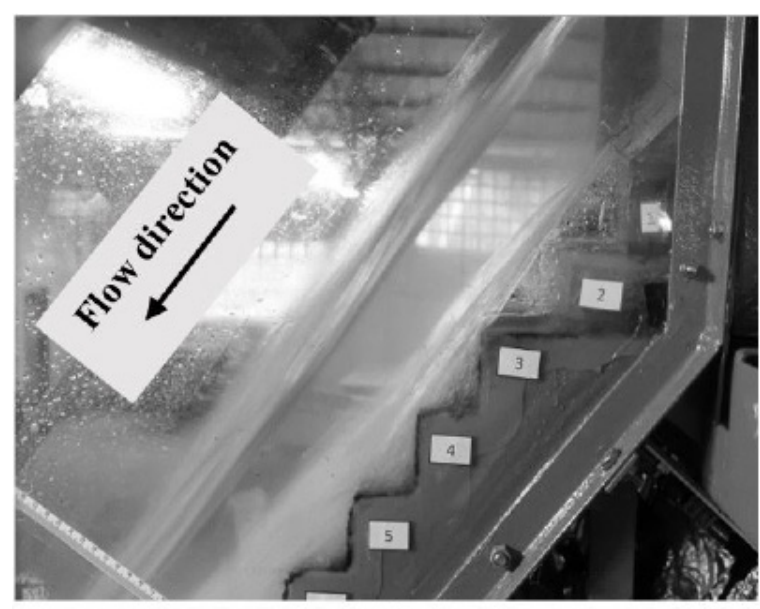

(a)

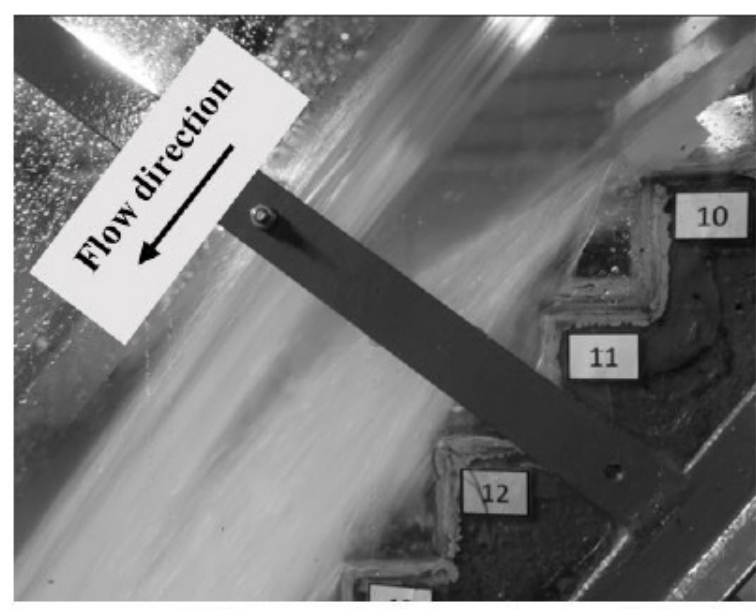

(b)

Figure 6. Flow appearance in (a) S1 and (b) S10 configurations, $q=0.40 \mathrm{~m}^{2} / \mathrm{s}$.

to the coefficients shown in Table 2) is in the order of $20 \%$, for the $\mathrm{S} 1$ condition the maximum differences can exceed $30 \%$. Therefore, envelope curves were constructed to the data obtained at the extreme water flows, considering the $\mathrm{S} 1$ condition, and the results of such adjustments are shown in Table 3. The envelope curves follow a second-degree polynomial function, as suggested by Equation 10. Applying the envelope curves at the limit water flows, the maximum differences between the measured and estimated pressure are now in the order of $20 \%$.

It is suggested that the greater dispersion of data in the $\mathrm{S} 1$ condition, when compared to the $\mathrm{S} 10$ condition, is related to the air-water mixture flow. As Figure 5 suggests, the greatest dispersion occurs especially for values of $\left(L_{-}-L_{j}\right) / h_{c}$ closer to zero, a region that is more influenced by the impact of the flow jet on the steps.

Figure 6 illustrates the appearance of the flow jet under $\mathrm{S} 1$ and $\mathrm{S} 10$ configurations, concerning $\mathrm{q}=0.40 \mathrm{~m}^{2} / \mathrm{s}$. In the $\mathrm{S} 1$ condition, it is possible to visualize an intact jet, constituted almost exclusively by water. In S10 condition, it is possible to identify that the lower portion of the flow jet is formed by an air-water mixture, possibly due to:

i) the higher air entry through the aerator system and consequent higher incorporation of air through the flow, compared to the $\mathrm{S} 1$ configuration;

ii) the higher flow velocity in the region, which makes inertial forces more prevalent than those of surface tension between air and water, than in the $\mathrm{S} 1$ condition.

It is understood that the uniformity in the air-water mixture of the S10 configuration has contributed to the occurrence of less dispersion in the results in the vicinity of the flow jet impact when compared to the S1 condition.
As Figure 5 suggests, the main differences between the behavior of S1 and S10 conditions occurred in regions close to the impact of the flow jet on the steps (vicinity of the position $\left(\mathrm{L}-\mathrm{L}_{\mathrm{j}}\right) / \mathrm{h}_{\mathrm{c}}=0$ ), whereas, from position $\left(\mathrm{L}_{-} \mathrm{L}_{\mathrm{j}}\right) / \mathrm{h}_{\mathrm{c}} \approx 6$, the $\Omega$ parameter assumes similar values in both induced aeration conditions.

\section{CONCLUSIONS}

The purpose of this work was to examine the pressures on the vertical faces of the steps and the air entrainment coefficient in a stepped spillway with an aerator system positioned in two different locations along the chute through an experimental study. Specific flows of 0.05 to $0.50 \mathrm{~m}^{2} / \mathrm{s}$ were analyzed in a channel with an angle of $53.13^{\circ}$.

The air entrainment coefficient $\beta$ increases with the positioning of the aerator system further downstream of the chute, as expected, as this is influenced by the increase in the Froude number of the flow. A new equation for the forecasting of $\beta$ coefficient is proposed (Equation 4, 3.0 $\leq \mathrm{Fr} \leq 6.0$ ), which proved to be adequate in predicting the air entrainment in aerator systems installed not only in the vicinity of the spillway crest but also downstream of the chute. In Equation 4, considering the installation of the aerator system further downstream of the chute, the flow depth in the deflector $\mathrm{h}_{0}$ can be estimated through the relationship proposed by Meireles et al. (2012), since it resulted in deviations not exceeding $5 \%$ of the measured depths.

The induced aeration does not substantially alter the magnitude of the hydrodynamic pressures on the vertical faces of the steps if compared with the values obtained under the natural aeration condition in the flow. However, the presence of the aerator system anticipates the occurrence of aeration in the flow, when compared to flow subject only to natural aeration, which should be recognized as a benefit, especially with regard to avoiding the occurrence of damage due to cavitation phenomenon. 
The proposed pressure prediction methodology, valid for the interval $0 \leq\left(\mathrm{L}-\mathrm{L}_{\mathrm{i}}\right) / \mathrm{h}_{\mathrm{c}} \leq 10$ and $3.0 \leq \mathrm{Fr} \leq 6.0$, resulted in a coefficient of determination in the range of 0.80 to 0.90 , which suggests an adequate agreement between the data and the adjustment. Concerning the magnitude of the measured pressures, the minimum absolute values of $\mathrm{P}_{0.1 \%}$ were about two or three times higher than $\mathrm{P}_{5 \%}$. Thus, depending on the purpose, the user must carefully select the probability to be considered in the prediction model and select the most extreme pressures whenever higher safety factors are prioritized.

The aerator system placed in the vicinity of the spillway crest can be a viable alternative for smaller dams. In the case of higher dams, the designer can indicate the best location of the aerator system, for example, based on the cavitation index. In these cases, installing the aerator system further downstream of the chute may be advantageous, since it allows the insertion of a greater amount of air into the flow. The selected site for the aerator system will depend on the conditions and design criteria adopted and should be evaluated on a case-by-case basis (see Appendix A).

Some of the results shown may be subject to non-negligible scale effects (see Appendix B) and should be analyzed with caution in case of transferring to the scale of real structures.

\section{ACKNOWLEDGEMENTS}

The authors are grateful to the National Council for Scientific and Technological Development (CNPq, Brazil), the Coordination for the Improvement of Higher Education Personnel (CAPES, Brazil), the Institute of Hydraulic Research (IPH/UFRGS, Brazil) and FURNAS Centrais Elétricas (Brazil) for providing the conditions and the financial support for the experimental works. The authors also thank the anonymous reviewers for the suggestions and discussions that considerably improved the manuscript.

\section{NOTATION}

The following symbols are used in this paper:

$\mathrm{a}, \mathrm{b}, \mathrm{c}=$ regression coefficients;

$\mathrm{Fr}=$ approach flow Froude number;

$\mathrm{Fr}^{*}=$ roughness Froude number;

$\mathrm{g}=$ gravitational acceleration $\left[9.806 \mathrm{~m} / \mathrm{s}^{2}\right]$;

$\mathrm{h}_{0}=$ water flow depth over the deflector $[\mathrm{m}]$;

$\mathrm{h}_{\mathrm{c}}=$ critical flow depth $[\mathrm{m}]$;

$\mathrm{h}_{\mathrm{i}}=$ inception aeration flow depth $[\mathrm{m}]$;

$\mathrm{h}_{\mathrm{s}}=$ step height $[\mathrm{m}]$;

$\mathrm{k}=$ step roughness $[\mathrm{m}]$;

$\mathrm{L}=$ longitudinal length along the chute, from the deflector position until the point under consideration $[\mathrm{m}]$;

$\mathrm{L}_{0}=$ longitudinal length along the chute, from the spillway crest until the deflector $[\mathrm{m}]$;

$\mathrm{L}_{\mathrm{i}}=$ longitudinal length along the chute, from the spillway crest until the inception point of natural aeration [m];

$\mathrm{L}_{\mathrm{j}}=$ jet length $[\mathrm{m}]$;

$\mathrm{P}=$ hydrodynamic pressure $[\mathrm{Pa}]$;

$\mathrm{P}_{\text {avg }}=$ average hydrodynamic pressure $[\mathrm{Pa}]$;

$\mathrm{P}_{\mathrm{v}}=$ vapor presure $[\mathrm{Pa}]$; $\mathrm{q}=$ specific discharge $\left[\mathrm{m}^{2} / \mathrm{s}\right]$;

$\mathrm{Q}_{\mathrm{a}}=$ air flow $\left[\mathrm{m}^{3} / \mathrm{s}\right]$;

$\mathrm{Q}_{\mathrm{w}}=$ water flow $\left[\mathrm{m}^{3} / \mathrm{s}\right]$;

$\operatorname{Re}=$ Reynolds number;

$\mathrm{t}=$ deflector height $[\mathrm{m}]$;

$\mathrm{V}=$ average flow velocity $[\mathrm{m} / \mathrm{s}]$;

$\mathrm{V}_{0}=$ average flow velocity over the deflector $[\mathrm{m} / \mathrm{s}]$;

We $=$ Weber number;

$\mathrm{Z}=$ flow energy parameter, from the critical energy line until the point under consideration $[\mathrm{m}]$;

$\alpha=$ chute angle $\left[^{\circ}\right] ;$

$\beta=$ air entrainment coefficient;

$\gamma=$ specific weight of water $\left[9806 \mathrm{~N} / \mathrm{m}^{3}\right]$;

$\theta=$ deflector angle $\left[{ }^{\circ}\right]$;

$\varrho_{\mathrm{w}}=$ density of water $\left[1000 \mathrm{~kg} / \mathrm{m}^{3}\right]$;

$\sigma=$ cavitation index.

Subscripts

$1=$ aerator system placed on step number 1 ;

$10=$ aerator system placed on step number 10 ;

$0.1 \%=0.1 \%$ probability;

$1 \%=1 \%$ probability;

$5 \%=5 \%$ probability.

\section{REFERENCES}

Amador, A., Sánchez-Juny, M., \& Dolz, J. (2009). Developing flow region and pressure fluctuations on steeply sloping stepped spillways. Journal of Hydraulic Engineering, 135, 1092-1100. http://dx.doi.org/10.1061/ (ASCE)HY.1943-7900.0000118.

Canellas, A. V. B. (2020). Pressões extremas atuantes nas proximidades das quinas dos degraus de vertedouros (Tese de doutorado). Programa de Pós-graduação em Recursos Hídricos e Saneamento Ambiental, Universidade Federal do Rio Grande do Sul, Porto Alegre.

Chanson, H. (1993). Stepped spillway flows and air entrainment. Canadian Journal of CivilEngineering, 20,422-435. http://dx.doi.org/10.1139/193-057.

Chanson, H. (2009). Turbulent air-water flows in hydraulic structures: dynamic similarity and scale effects. Environmental Fhid Mechanics, 9, 125-142. http://dx.doi.org/10.1007/s10652-008-9078-3.

Chanson, H. (2015). Discussion of "Cavitation Potential of Flow on Stepped Spillways” by K. Warren Frizell, Floriana M. Renna, and Jorge Matos. Journal of Hydraulic Engineering, 141, http://dx.doi.org/10.1061/ (ASCE)HY.1943-7900.0000808.

Falvey, H. T. (1990). Cavitation in chutes and spillways (Engineering Monograph, No. 42, 145 p.). Washington: Bureau of Reclamation.

Ferla, R., Priebe, P. S., Novakoski, C. K., Dai Pra, M., Endres, L. A. M., Marques, M. G., Teixeira, E. D., Sanagiotto, D. G., Castiglio, G. S., Rocha, D. R., Paim, L. S., Gessi, L. C., Bassegio, P. G. M., Vilar, S. A. P., \& Canellas, A. V. B. (2019). Stepped spillway with pre-aeration: mean pressures and jet's reach. In Anais do XXIII Simpósio Brasileiro de Recursos Hídricos. Foz do Iguaçu: ABRHidro. 
Frizell, K. W., Renna, F. M., \& Matos, J. (2013). Cavitation potential of flow on stepped spillways. Journal of Hydraulic Engineering, 139, 630-636. http://dx.doi.org/10.1061/(ASCE)HY.1943-7900.0000715.

Heller, V. (2011). Scale effects in physical hydraulic engineering models. Journal of Hydraulic Research, 49, 293-306. http://dx.doi.org/10.1080/ 00221686.2011 .578914$.

Kells, J. A., \& Smith, C. D. (1991). Reduction of cavitation on spillways by induced air entrainment. Canadian Journal of Civil Engineering, 18, 358-377. http://dx.doi.org/10.1139/191-047.

Marques, M. G., Ferla, R., Novakoski, C. K., Dai Pra, M., Teixeira, E. D., Endres, L. A. M., Prestes, A. C., Moraes, P. J., Rigo, A. F., \& Canellas, A. V. B. (2019). Stepped spillway flow: pre-aeration with deflector. In Proceedings of the 38th LAHR World Congress. Panamá: IAHR.

Matos, J., \& Meireles, I. (2014). Hydraulics of stepped weirs and dam spillways: engineering challenges, labyrinths of research. In Proceedings of the 5th International Symposium on Hydraulic Structures. Brisbane: The University of Queensland. http://dx.doi.org/10.14264/uql.2014.11.

Meireles, I., Renna, F., Matos, J., \& Bombardelli, F. (2012). Skimming, nonaerated flow on stepped spillways over roller compacted concrete dams. Journal of Hydraulic Engineering, 138, 870-877. http://dx.doi. org/10.1061/(ASCE)HY.1943-7900.0000591.

Mojtaba, S., Jahromi Habib, M., Bajestan Mahmood, S., Alireza, M., \& Heidar Ali, K. (2015). Experimental study of effect of installing deflector on replacement of inception point of air entrainment in stepped spillways. Journal of Scientific Research and Development, 2(4), 11-16.

Novakoski, C. K., Ferla, R., Dai Prá, M., Canellas, A. V. B., Marques, M. G., \& Teixeira, E. D. (2020). Stepped spillway with pre-aeration by a deflector: flow characteristics. Revista Brasileira de Recursos Hidricos, 25, e26. http://dx.doi.org/10.1590/2318-0331.252020190051.

Osmar, F. M., Canellas, A. V. B., Priebe, P. S., Saraiva, L. S., Teixeira, E. D., \& Marques, M. G. (2018). Analysis of the longitudinal distribution of pressures near the ends of the vertical and horizontal faces in stepped spillway of slope 1V:0.75H. Revista Brasileira de Recursos Hidricos, 23, e4. http://dx.doi.org/10.1590/2318- 0331.0318170057.

Peterka, A. J. (1953). The effect of entrained air on cavitation pitting. Minneapolis: International Association for Hydraulic Research and Hydraulics Division.

Pfister, M., \& Boes, R. M. (2014). Discussion of "Skimming, Nonaerated Flow on Stepped Spillways over Roller Compacted Concrete Dams" by Inês Meireles, Floriana Renna, Jorge Matos, and Fabián Bombardelli. Journal of Hydraulic Engineering, 140(10), 07014012. http://dx.doi. org/10.1061/(ASCE)HY.1943-7900.0000753.

Pfister, M., \& Chanson, H. (2014). Two-phase air-water flows: scale effects in physical modeling. Journal of Hydrodynamics, 26, 291-298. http://dx.doi.org/10.1016/S1001-6058(14)60032-9.

Pfister, M., \& Hager, W. H. (2010a). Chute aerators. I: air transport characteristics. Journal of Hydraulic Engineering, 136, 352-359. http:// dx.doi.org/10.1061/(ASCE)HY.1943-7900.0000189.

Pfister, M., \& Hager, W. H. (2010b). Chute aerators. II: hydraulic design. Journal of Hydraulic Engineering, 136, 360-367. http://dx.doi.org/10.1061/ (ASCE)HY.1943-7900.0000201.

Pfister, M., Hager, W. H., \& Minor, H. (2006a). Bottom aeration of stepped spillways. Journal of Hydraulic Engineering, 132, 850-853. http:// dx.doi.org/10.1061/(ASCE)0733-9429(2006)132:8(850).
Pfister, M., Hager, W. H., \& Minor, H. (2006b). Stepped chutes: preaeration and spray reduction. International Journal of Multiphase Flow, 32, 269-284. http://dx.doi.org/10.1016/j.ijmultiphaseflow.2005.10.004.

Pinto, N. L. S. (1984). Model evaluation of aerators in shooting flow. In H. Kobus (Ed.), Scale effects in modelling bydraulic structures. Esslingen: Technische Akademie.

Sánchez-Juny, M., \& Dolz, J. (2005). Experimental study of transition and skimming flows on stepped spillways in RCC dams: qualitative analysis and pressure measurements. Journal of Hydraulic Research, 43, 540-548. http://dx.doi.org/10.1080/00221680509500152.

Sánchez-Juny, M., Bladé, E., \& Dolz, J. (2007). Pressures on a stepped spillway. Journal of Hydraulic Research, 45, 505-511. http:/ /dx.doi.org/1 0.1080/00221686.2007.9521785.

Sánchez-Juny, M., Bladé, E., \& Dolz, J. (2008). Analysis of pressures on a stepped spillway. Journal of Hydraulic Research, 46, 410-414. http:// dx.doi.org/10.3826/jhr.2008.3152.

Tassinari, L. C. S., Sanagiotto, D. G., Marques, M. G., Lauffer, L. L., \& Trierweiler Neto, E. F. (2020). Combination of experimental and numerical approaches to determine the main characteristics of skimming flow in stepped spillways. Revista Brasileira de Recursos Hídricos, 25, e3. http://dx.doi.org/10.1590/2318-0331.252020190070.

Terrier, S. (2016). Hydraulicperformance of stepped spillway aerators and related downstream flow features. (Communication 63). Lausanne: Laboratoire de Constructions Hydrauliques, Ecole Polytechnique Fédérale de Lausanne.

Volkart, P., \& Rutschmann, P. (1984). Air entrainment devices (air slots). Zurich: Mitteilungen der Versuchsanstalt für Wasserbau, Hydrologie und Glaziologie.

Zamora, A. S., Pfister, M., Hager, W. H., \& Minor, H. (2008). Hydraulic performance of step aerator. Journal of Hydraulic Engineering, 134, 127134. http://dx.doi.org/10.1061/(ASCE)0733-9429(2008)134:2(127).

\section{Authors contributions}

Rute Ferla: Literature review, physical model tests, methodology elaboration, data analysis and writing of the manuscript.

Carolina Kuhn Novakoski: Physical model tests, methodology elaboration, data analysis and paper review.

Priscila dos Santos Priebe: Conception of the physical model, physical model tests and paper review.

Mauricio Dai Prá: Physical model tests, data analysis and paper review.

Marcelo Giulian Marques: Conception of the physical model, methodology elaboration, data analysis and paper review.

Eder Daniel Teixeira: Methodology elaboration, data analysis and paper review.

Editor-in-Chief: Adilson Pinheiro

Associated Editor: Edson Cezar Wendland 


\section{APPENDIX A. DEFINITION OF THE AERATOR SYSTEM POSITION}

The estimation of the most desirable position for installing the aerator system in a spillway can be done by evaluating the cavitation index ( $\sigma$, Equation A1). When $\sigma$, for a certain chute location, is lower than the cavitation index considered critical $\left(\sigma_{c}\right)$, then the installation of an aerator system may represent an interesting alternative to avoid the damage resulting from cavitation.

$\sigma=\frac{P-P_{v}}{\rho_{w} \frac{V^{2}}{2}}$

where $\sigma$ is the cavitation index, $\mathrm{P}_{\mathrm{v}}$ is the vapor pressure $[\mathrm{Pa}]$ and $\mathrm{V}$ is the average flow velocity $[\mathrm{m} / \mathrm{s}]$.

The $\sigma_{c}$ index for stepped spillways is more conservative than for smooth channels. Pfister et al. (2006a), for example, indicate $\sigma_{c}$ of about 0.90 in the vicinity of the first step of the chute, supported by the contributions of Falvey (1990) and the consideration that the step represents an abrupt irregularity on the structure surface. Frizell et al. (2013), based on acoustic measurements, defined as $\sigma_{c}$ values in the order of 0.35 and 0.63 , respectively, for stepped chutes with $\alpha=22^{\circ}$ and $68^{\circ}$. Pfister \& Boes (2014) suggested $\sigma_{\mathrm{c}}$ from 0.50 to 0.70 , for channels with steps of $0.30 \mathrm{~m}$ and $1.20 \mathrm{~m}$ in height and $\alpha=50^{\circ}$. The authors obtained these limits based on the consideration of Amador et al. (2009), which indicate maximum specific flows in the order of $15 \mathrm{~m}^{2} / \mathrm{s}$ over stepped spillways, in order to avoid the occurrence of cavitation.

Figure A1 shows the $\sigma$ index determined according to the data measured in the present work, concerning the flow in a real structure, regarding the geometric scales of 1:10, 1:15 and 1:20. To determine the acting pressure $(\mathrm{P})$, it was considered the statistical parameter of average pressure $\left(\mathrm{P}_{\text {avg }}\right)$ collected on the vertical face of the steps, in the natural aeration condition. The velocity $\mathrm{V}$ was determined considering the flow depth measured in each of the respective steps.

Considering Figure A1 and $\sigma_{c}$ extremes of 0.90 (Pfister et al., 2006a) and 0.50 (Pfister \& Boes, 2014), the results indicate that the aerator system can be an interesting alternative both when installed in the vicinity of the first steps, as well as in downstream steps (the results are lower than the indexes considered critical).

$\Delta \quad 1: 10 \quad \times \quad 1: 15 \quad \bullet \quad 1: 20-\quad-$ oc Pfister et al. (2006a) ..... oc Pfister and Boes (2014)

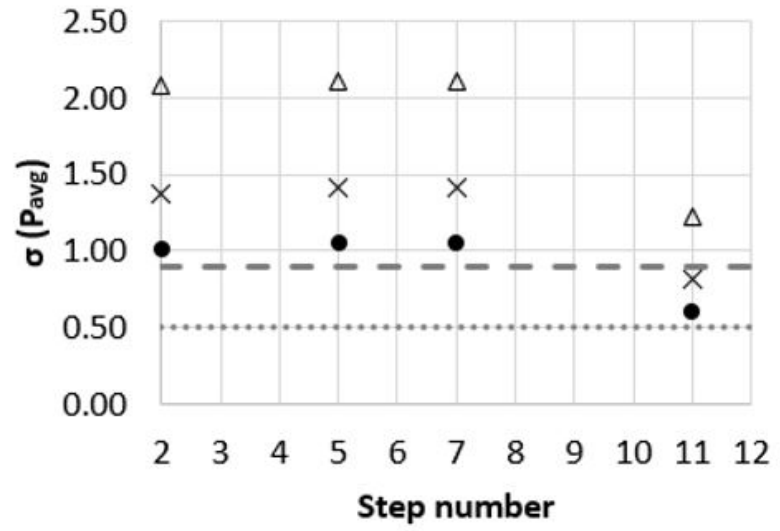

(a)

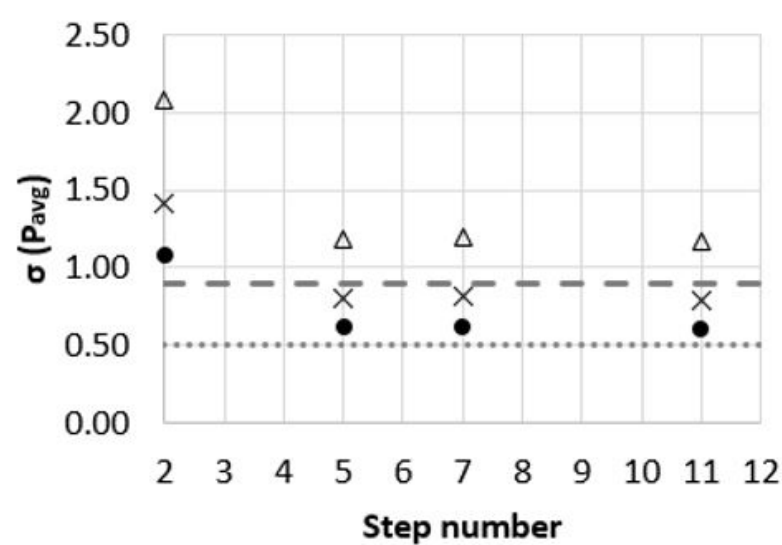

(b)

Figure A1. Cavitation index versus step number, for model scale from $1: 10$ to $1: 20$, where (a) $\mathrm{q}=0.20 \mathrm{~m}^{2} / \mathrm{s}$ and $(\mathrm{b}) \mathrm{q}=0.50 \mathrm{~m}^{2} / \mathrm{s}$. $\mathrm{P}_{\text {avg }}$ is the average hydrodynamic pressure $[\mathrm{Pa}]$. 


\section{APPENDIX B. SCALE EFFECTS}

The Froude similarity between model and real structure is adopted in the physical modeling of free surface flows, where the movement is predominantly ruled by the gravity force. However, in air-water flows, viscosity and surface tension also interfere in the flow (Heller, 2011; Terrier, 2016). The dimensionless parameters that represent viscous forces and surface tension are, respectively, the Reynolds and Weber numbers (Re and We).

Pfister \& Hager (2010a) and Pfister \& Chanson (2014) compiled the main considerations that suggest limit recommendations for Re and We numbers so that the scale effects can be considered negligible. In studies involving aerators and two-phase flow over spillways, according to the authors, considering $\mathrm{h}_{0}$ as the reference lenght, the recommended limits cover, on average, Re $>1 \mathrm{x} 10^{5}$ to $\operatorname{Re}>2.2 \times 10^{5}$, We $>110$ to We $>170$.

The present study resulted in $\operatorname{Re}>2 \times 10^{5}$ and We $>90$, considering the tests where $\mathrm{q}>0.20 \mathrm{~m}^{2} / \mathrm{s}$. For the tests in which $\mathrm{q}<0.20 \mathrm{~m} / \mathrm{s}$, the results are in the range of $5.4 \times 10^{4}<\operatorname{Re}<1.5 \times 10^{5}$ and $50<\mathrm{We}<80$ and, therefore, may be subject to non-negligible scale effects, especially concerning the influences of surface tension in situations of lower specific flows.

It should be noted, however, that the surface tension force, represented by the We number, is overestimated in physical models that satisfy the similarity of the Fr number (Chanson, 2009; Pfister \& Hager, 2010a). Thus, the results obtained in the model are favorable to safety, since they underestimate the air transport when compared to the prototype.

Scale models from 1:10 to 1:15 should be considered to reduce the effects of surface tension on the results (Pinto, 1984), while models not smaller than 1:25 should be employed to evaluate the characteristics of aeration systems (Volkart \& Rutschmann, 1984). 